\title{
Research on the Judicial Application of Legal Principles
}

\author{
Feifei Lin
}

\author{
Beihua University Law School, no.3999, \\ hua shan road, jilin city, jilin province, China \\ linfeifei_beihua@163.com
}

Keywords: Legal principles; Judicial application

\begin{abstract}
At present, China's social and legal relations are more complex and some issues need to be resolved. Therefore, it is particularly important to give full play to the advantages of the law in the judicial field. This paper proceeds from the judicial application value of legal principles, further analyzes the application of legal principles in China's judicial practice and finally puts forward perfect methods for the judicial application of legal principles in China.
\end{abstract}

\section{The Judicial Application of Legal Principles}

As a product of social life, it is necessary to follow the actual development of society when formulating laws. However, the pace of economic development is often faster than the pace at which the law is drafted, resulting in existing laws cannot fully resolve the problems. Once this happens, the judge will seek appropriate legal principles to ensure the impartiality of the referee case. Although there is controversy, the role of legal principles cannot be ignored.

Legal principles have a guiding role in judicial activities. Legal principles, as an important support of the legal system, can bring together decentralized legal rules and play a key role in forming a complete legal system. The use of legal principles in carrying out referee has relative stability, at least it can be achieved by law. Due to the guiding role of legal principles, the judgments made according to legal principles are more easily accepted and convinced. At the same time, the adoption of legal principles in making judgments can better maintain the stability of social life and the harmony of social relations.

\section{The Application of Legal Principles in Judicial Practice of China}

Arbitrary of the Judicial Application of Legal Principles. Legal principles are a very important part of the legal system and can be seen throughout the legal system. Many legal books and articles in our country provide the legal principles contained in this law in General Regulations as the guidance of the law in the practice process. As social codes of conduct, legal and moral influence permeate each other. Many legal principles are based on the evolution of morality, which makes the legal principles be more abstract and be difficult to be accurately and directly applied in cases. Therefore, the judge must explain the reasons for their application when applying legal principles, and they must explain the meaning and expansion of principles in specific cases and shall have a clear grasp of the scope of application.

However, in real life, although the judge will propose which legal principle will be applied specifically to the case, it is simply to list out the general rules of the law mechanically and it is impossible to give deep reasons or rational reasoning processes. This kind of application method has no point in the progress of justice. The legal principles can be easily defeated because they cannot be frustrated without justification. It can be seen that the judge's application of legal principles in a case is very randomly.

For simple cases, the judge should first rule according to legal rules. When dealing with controversial cases, related legal principles that are ambiguity or cannot specify the problem shall not be applied. It can be seen that the legal rules are the principle of priority application. Because the definition of the field and the limit of application of the legal principles is not clear, the judge will be influenced by subjective factors and has too much power in a case. The public will have 
concerns that the arbitrary use of legal principles in the judicial process will make judgments be unfair. People's consciousness exceeds the constraints of the law, and subjective judgments and power abuses occur.

Most of the legal principles have a clear boundary and they have evolved from ethics. Therefore, it is difficult for legal principles to target specific cases. Therefore, it is relatively difficult to select legal principles as the basis for judges to handle cases.

The Impact of the Application of Legal Principles on the Stability of Laws. The application of legal principles reduces the credibility of the law.The legal principle itself has no definite rules, and there is no definite basis for the judgment of the entire legal event. In the judge's process of judgment, excessive power will cause the public to question the judge's reasoning. To analyze the role of legal principles in the credibility of the law, we must first exclude the following situations: Cases of all levels of courts in the first instance, only the court of final trail can invoke legal principles. Cases of courts in the first, second and third instance, only the retrial courts can invoke laws.

Many existing cases show that most of the cases that applied legal principles in the first instance were recognized by the parties and the court of final trail, and only a small number of cases revised the unreasonable application of legal principles. In spite of this, many people still feel that the abstractness of legal principles will have an adverse effect on the credibility of the law.

Elimination of legal stability due to individual cases.The goal of the judicial system is to ensure social stability and fairness and justice, and to maintain the consistency of value goals and legal stability from the side. However, in the processing of individual case, people will find a situation that is contrary to the stability of the law: when using legal principles to judge a case, in order to pursue values of fairness and justice, the judge will break the consistency of the judicial system. Stability will also be adversely affected to a certain degree, which creates a conflict between the application of the legal principles for the pursuit of fairness and justice and the stability of the judicial system. Starting from the purpose of the law, fairness, justice, and legal stability are unified. However, in the introduction of legal principles in the judicial process, judges must strive to find a balance between the two, to ensure the fairness of the case without completely sacrificing the stability of the law, and as far as possible to achieve the coordination and unity of the two.

Otherwise, it will lead to unfair judgement of the case or the destroy to the stability of the law. If the two cannot be coordinated, the law will be more and more difficult to limit the public, in addition, it has to pay a huge price to restore people's identity to the legal authority.

\section{Perfection of Judicial Application of Legal Principles of China}

Perfection of Legal Principles of Judicial Applicable Theory. Clear the theoretical essence of legal principles. China has an extremely long history of legal actions and code formation. However, for a long term, legal actions have not spawned a complete legal system. It can also be said that the theoretical basis in this system is weak. The deep foundation of the traditional Chinese Confucian culture makes moral constraints be far better than legal constraints. It is precisely for this reason that China has not developed a clear theory of legal principles. Since modern times, the ideas of foreign legal scholars have flowed into China, forming a certain amount of legal people in China. The influence of legal principles has gradually emerged, but its status and role have only remained at the theoretical level. In the course of trial of a case, if the judge does not have sufficient knowledge and understanding of the contents of the legal principles of the cases which the existing legal rules do not apply, it is difficult to determine whether the case applies to a legal principle when the legal principle is applied. Under the applicable conditions, how should we grasp the meaning of legal principles and determine the conditions and environment for the application of legal principles?

Clear the contents of legal principles.Relevant personnel engaged in the legal profession of our country have not fully grasped the theoretical principles of legal principles, which has also resulted in certain restrictions on the application of legal principles in our country. What is even more crucial is that there are many problems in the understanding of the contents and the content 
development of legal principles by the personnel engaged in the legal profession in China. Because of this, we need to clearly define the contents of legal principles so that legal principles can have more significant effects in judicial field.

There are two forms of legal principles, namely: the actual and non-factual legal principles. In the actual application process, it is of course first to select the actual legal principle as the adjudication criteria to apply to special cases. Of course, not all actual legal principles can be applied as judicial basis of judicial activities. According to the formulation of the legal principle of actual legality, China's legal system will be divided into public rationality principles and policy principles. Public rationality principle is based on the principle of legal principles, or it is a legal principle derived from specific cases, such as people's familiarity with the principles of honesty and trustworthiness, principles of fairness and justice and so on. Policy principles are related to social progress and development, such as the principle of "ruling the country by law" and the principle of "family planning". In general, public rationality principle can be used as a basis for case judgement, but the principles should be concrete. It is mainly because of the abstractness of policy principles and they are not easy to give an explanation when being used as the basis of judgment.

The types of legal principles.For specific cases, legal principles are not explained in detail. In order to avoid unnecessary and erroneous results in the use of legal principles, we use induction to summarize and divide legal principles into several categories, and make clear division to each type of cases which each principle is applied in. Although the cases and cases are not exactly the same, to some extent, many cases have the same characteristics. Therefore, understanding the common grounds of the same type of cases makes the judges know what kind of laws can be used for these cases, which can reduce the disagreements in case trials and the labor intensity in the trial process.

The type of legal principles is to classify and specify the theory on the basis of facts. Therefore, the type of legal principles is of great significance to the application in judicial cases. The type of legal principles is an abstract concept. It summarizes the facts and the characteristics of cases that apply to the same legal principle, and proceeds from the essential characteristics of the fact. The mastery of the fact of legal principles can help the judge to make justified and reasoning trail when dealing with the case with special nature.

Perfection of Legal Principles of Judicial Applicable Practice. Establish a judicial application model of legal principles.In the use of legal rules for trials, there are legal provisions for reference.

When using legal principles for the trial, "profile spectrum" which corresponding principles apply to should also be constructed for the judges to reference. Relying on the summary of cases of applicable legal principles in announcement, the establishment of "pattern spectrum" applicable to the principles can serve as a referee's result for judges dealing with similar cases, which will not only ensure the fairness and impartiality of the trial, but also improve the unity and credibility of judiciary.

The court summarizes the cases and sums up the ones of common violations of good faith, which are mainly divided into the following aspects: first, violation of credit or breach of contract to obtain rights; second, in the process of exercising certain rights, violate rules stipulated by the legal system and obtain certain things that he does not have the right to claim. Third, when he exercises his rights, he contradicts his own behavior. However, if others trust in his previous behavior, it is a violation of good faith.

The establishment of judicial application of the type of legal principle can be based on the case judged by the Supreme Court and typical cases reported by courts at all levels of the country.

Strengthen the concept of "legal conscience" of judges.A fair and justice trial of a case depends on how the judge of the case makes the judgement. General cases can be settled by applying legal rules. For special difficult cases, judges need to use their own solid theoretical foundation and rich experience accumulated over many years to judge on the basis of legal principles. The legal principle is not like the rules of the law which can provide a more detailed basis for judges. In view of the current use of legal principles in China is not very common, it is more necessary for judges to explain the legal principles of application. First of all, use legal principles to conduct trials. Take the first step and accumulate rich experience in order to apply legal principles to be reasonable and fair. 
Strict legal principles judicial applicable steps.First, the judge should first classify the principles that apply to the actual cases. There are many principles in the legal system, but the legal applicability of these principles is not the same. When judges use legal principles, they should consider the application of non-factual legal principles on the basis of actual legal principles, and should also pay attention to the use of legal principles and policy principles. Judges need to carefully identify legal principles that suit the individual case and use them rationally according to the actual situation.

Second, the judge fully infers and analyzes the case, finds a justified reason to apply legal principles, and satisfies the necessary theoretical conditions for application. In the process of judging a case, the judge should fully grasp the details of the case and attempt to analyze the case against the rules that may be used. Only when all the legal rules cannot explain the case well, which means the rules are vague, conflicted, reversed or are left blank, can legal principles be applied to cases. Only when the application of the exact argumentation rules will result in the destruction of the fairness and justice of the case, can the legal principle be adopted to ensure the consistency of the law principles and the spirit of justice.

Again, the judge can give a reasonable explanation of the legal principles in the case of judicial application. Since the application of legal principles has inferred the case and the final decision, the judge should give an explanation that convinces everyone. Only when the judge has found out the essence of legal principles can a thorough analysis of the case be made so that the judgement can be convincing.

The nature and extension of legal principles have the characteristics of openness and universal application, making it difficult to define the application fields. In the trial of the case, the judge shall give a reasonable and specific explanation of the application of the principle in accordance with the circumstances of the case.

The development of modern China is changing with each passing day. The diversification of culture and beliefs has become increasingly evident in China. The scope of application of universally applicable laws and regulations is smaller and smaller. Judges have to make decisions on the spot and the accurate predictability has become impossible. Therefore, the subjective role of judges should be brought into full play, and that legal principles should be used flexibly. Because of this, in the complicated social life, the unchanging legal nature and the avoidance of subjective arbitrary are still the rules that personnel engaged in the legal profession should adhere to.

This paper focuses on the judicial application of legal principles. It can be seen from the discussion of this paper that there are some deficiencies in the judicial application of legal principles that need to be improved. Continuously improve the applicable conditions of legal principles and make legal principles fit in with the legal rules. In the process, a rational and distinctive legal system is gradually formed and the judge's sense of identity is enhanced. In addition, it is necessary to establish corresponding systems, etc. to give judges proper authority so that they can better resolve new types of disputes, make up for the lack of laws in time and avoid the occurrence of legal rulings.

\section{References}

[1] X.Y. Hou: Study on the Application of Legal Principles from the Perspective of Context. Qingdao University of Science and Technology, 2017-06-11

[2] Q.L. Cui: On the application of legal norms. Kunming University of Science and Technology, 2017-05-01

[3] Y.Q. Sun: The judicial application of credit principles. Shandong University, 2016-05-20

[4] Q. Wei: On the Application of Proportional Principle in Administrative Judgment. Central University for Nationalities, 2016-04-20

[5] X. Huang: Study on Benefits of Civil Appeal. Southwest University of Political Science and Law, 2015-09-28

[6] X. Yang: Study on the Judicial Application of the Closest Relation Principle in China. Jilin University, 2016-03-01 
[7] H.C. Yang: Research on the Judicialization of Human Rights. Wuhan University, 2016-05-01

[8] Li Chuaning. An Inquiry into Substantial Reasoning in Judicial Application. Yantai University, 2017-04-11

[9] C.C. Wang: On the Principles and Limitations of Freedom of Criminal Evidence in France. Southwest University of Political Science and Law, 2016-03-01

[10] Q. Li: Study on Procuratorial Organs' Investigative and Verification Rights in Civil Action. Nanjing Normal University, 2016-05-28 